\title{
Rural Teachers' Quality of Work Life (QWL) in China: The Case of Shanxi Province
}

\author{
Dong Yang \\ Jiayi Lu
}

Key Research Institute of Humanities and Social Sciences at University, Center for Studies of Education and Psychology of Ethnic Minorities in Southwest China Southwest University, Chongqing, China Email:121179746@qq.com

\section{Doi:10.5901/ajis.2014.v3n4p39}

\begin{abstract}
The Teacher's Quality of Work Life (QWL) factors were identified as respect needs, survival needs, security needs and self-actualization needs separately. This paper analyze rural teacher's QWL from these five dimensionalities, and combined with methods such as questionnaires, interviews, observations, empirical research on the quality of work life of rural primary and secondary school teachers in Shanxi Province, the findings indicate that the quality of life of rural primary and secondary school teachers in Shanxi Province is in the lower-middle level, mainly manifested in imbalances of economic income and workload, leisure life, family care and things like poor teaching physical environment, limited democratic participation and management, deficiency of relevant rights and interests protection, limited chances of professional development and selfrealization. In addition, it discussed the possible solutions through the analysis of the present situation.
\end{abstract}

Keywords : teacher's quality of work life rural teachers primary and secondary school

\section{Introduction}

As a special occupation, teachers' quality of work life can not only have affect on their own development, but also on students and even the educational development. In China, things like teachers' teaching environment, wage and treatment, living and working conditions in rural areas are still dissatisfactory, when compared with those of city teachers. Sun Yuhua (2007) put that: "To truly understand the conditions of rural teachers, we should put them into a real social living environment". Through the study on the work life conditions of rural teachers, we try to probe into the countermeasures for improving their quality of work life and mobilize positivity, in order to achieve the goal of stabilize their morale and retain talent, thus, improve the overall quality of rural teachers and boost the continuous development of education.

Wang et al (2012) hold that "the quality of work life refers to the individual feelings in terms of work scope, in which aspects like fair and ample recompense, safe and healthy working conditions, sense of security, democratic management, personal relationships, the mean toward individual lives, etc, are included." Teacher quality of work life means the various feelings and experiences teachers gained in school, it is realized by school offering teachers the necessary needs both materially and mentally, this kind of teacher-needed satisfaction can generate more positive experience and makes them more autonomous in work, also increase their sense of ownership and responsibility, enhance their degree of participation and satisfaction in work, all that contribute to the success of reaching school objectives. Luo Ruguo, (2012) discussed the three stages of QWL research in China: the preparing period (before 2003), developmental stage (2004-2008), and depending stage (2009-now) and analyzed research hotpots in home and abroad Some scholars surveyed teachers' quality of work life in primary and secondary school (Wang Lihua, Xu Changjiang, Zhu Yuhua et al. 2012). Some scholars made a survey on relationship between young university teachers' occupation slack and their QWL (Cai Xiaowu \& Liao Chuanjing.2013). Sun Yuhua et al, (2008) summed up the international research progress of QWL from aspect of teachers' comprehensive and humorous development.

Through numerous scholars have studied teacher's QWL from different angles, yet there are less research on teacher's QWL in rural areas, especial those in central and west rural areas, for regions like this, more focus should be attached on as the poor conditions and environments they are facing. Shanxi Provence, which located in central China and lies to the west of Taihang Mountain, is a relatively poor region in compared with provinces next to it. In addition, 
recently, there are more and more school incidents happen in primary and middle schools, the majority of people just pay close attention to things like children' security and education quality, yet less emphasis on teacher's quality of work life. This research aims at finding out the real conditions and problems existed there in terms of rural teacher's QWL and hope to contribute to the current researches by offering some practical suggestions.

\section{Research Design}

\subsection{Research object}

Choosing primary and middle school teachers of rural areas in Shanxi Provence as the research objects, 300 questionnaires were handed out during the research, among those 239 valid questionnaires were collected, giving the recovery rate of $77.96 \%$. The basic information of research objects are as follows: 87 are male, 152 are female; 197 are married, unmarried number are 41; 171 work in primary school, 67 work in middle school; 209 are state-run teachers, and 30 are supply teachers. Teachers' education background distribution: 18 hold the degree of secondary normal school or below, 134 are college graduates and 87 hold a bachelor degree or above; in terms of economic income distribution, most of the participants, say as much as $77.41 \%$, reported that their annual income are around 10,000RMB to 30,000RMB; for teacher' sonority, 95 teachers have worked for 16 years or above, 92 of them reported a working experience of 6 to 15 years and 51 are under 5 years.

\subsection{Research tools}

We choose the Teachers' Quality of Work life Questionnaires edited by Zhao Shouying et all (2010) of Guizhou Normal University as research questionnaire, the included 35 items are connected with Maslow's hierarchy of needs theory, the five needs are named as follow according its content: 1, esteem needs, 2, social needs, 3, existence needs, 4, security needs and 5, self-actualization needs. By using five points scoring method, all the items are ranging from 1 to 5 points, which stands for 'not meet al all' to 'totally match', the sum of that five dimensionalities makes up the total points, which located between 35 to 245 , the more scoring means more satisfaction in typical aspect while the less score means the opposite .

\subsection{Data processing}

The research use IBM SPSS statistics 19.0 to process and analyze data, during this process, statistic approaches like descriptive statistics, independent-sample $T$ test and variance analysis are mainly used.

\section{Questionnaire Survey Result and Analysis}

\subsection{The overall condition analysis}

Table 1 : The descriptive statistic of 5 dimensionalities and TP

\begin{tabular}{|l|c|c|c|c|}
\hline \multicolumn{1}{|c|}{ Dimensionality } & Mean value & Standard deviation & Minimum value & Maximum value \\
\hline Esteem needs & 24.93 & 5.459 & 10 & 34 \\
\hline Social needs & 29.46 & 3.485 & 19 & 35 \\
\hline Living needs & 22.98 & 5.837 & 8 & 34 \\
\hline Security needs & 25.45 & 4.671 & 12 & 35 \\
\hline Self-actualization & 27.08 & 4.456 & 12 & 35 \\
\hline Total points (TP) & 119.89 & 20.425 & 75 & 165 \\
\hline
\end{tabular}

It can see from table 1 that the overall score of quality of work life of rural primary and middle school teachers in Shanxi Province is 119.89, a lower middle level; for mean value, the sequence is living needs, esteem needs, security needs, self-actualization and social needs separately from big difference to small. For the average of those 5 dimensionalities, living needs reports the lowest score, the reason lies in teacher's dissatisfaction about their salary when compared with other occupations, this may indicated their willing of improving treatment, also, it is suggested that the educational 
authorities should pay close attention to this on rising issue. Teachers' needs of esteem is also relatively low, which perfectly explains the current social status and job reputation of rural teachers in China; then comes the security needs, it goes quiet comparatively ideal as government and society take it seriously all the time and many security procedures have released by them, in addition, student's aggressive behaviors toward teachers are rarely happed in rural schools. Rural teachers score the highest regard to social needs; which can be best explained by teachers' role of communication with various people, say, teacher-student communication, teacher -parent relationship and socializing with their own colleagues.

\subsection{The difference examination of teachers' opinion in terms of quality of work life.}

After the questionnaires were reclaimed, firstly a difference examination was undertaken, for terms like gender, marital status and teacher identity, independent-sample t-test was conducted, while for aspects like educational background, seniority, economical income, school type, nature of the school, one-way analysis of variance was conducted, then take the inspection results as reference of the analysis, the results are as follow:

Table 2: the difference examination results ( $P$ value)

\begin{tabular}{|l|c|c|c|c|c|}
\hline $\begin{array}{l}\text { Teacher's quality of work } \\
\text { life }\end{array}$ & $\begin{array}{c}\text { Gender } \\
\text { T }\end{array}$ & $\begin{array}{c}\text { Marital status } \\
\mathrm{T}\end{array}$ & $\begin{array}{c}\text { Teacher identity } \\
\mathrm{T}\end{array}$ & $\begin{array}{c}\text { Seniority } \\
\mathrm{F}\end{array}$ & $\begin{array}{c}\text { Educational background } \\
\mathrm{F}\end{array}$ \\
\hline Esteem needs & 0.003 & 0.298 & 0.085 & 0.238 & 0.008 \\
\hline Social needs & 0.015 & 0.231 & 0.024 & 0.325 & 0.068 \\
\hline Living needs & 0.000 & 0.758 & 0.004 & 0.959 & 0.001 \\
\hline Security needs & 0.121 & 0.668 & 0.250 & 0.796 & 0.000 \\
\hline Self-actualization & 0.004 & 0.329 & 0.098 & 0.421 & 0.016 \\
\hline & Position & Economical income & School type & Nature of school & Teaching subject \\
\hline Esteem needs & $\mathrm{F}$ & $\mathrm{F}$ & $\mathrm{F}$ & $\mathrm{F}$ & $\mathrm{F}$ \\
\hline Social needs & 0.005 & 0.339 & 0.000 & 0.036 & 0.117 \\
\hline Living needs & 0.137 & 0.728 & 0.000 & 0.105 & 0.209 \\
\hline Security needs & 0.227 & 0.462 & 0.006 & 0.013 & 0.516 \\
\hline Self-actualization & 0.109 & 0.630 & 0.006 & 0.019 & 0.213 \\
\hline
\end{tabular}

Note: $\mathrm{P}>0.05$ means the difference is non-significant, $\mathrm{P}<0.05$ means significant difference, while $\mathrm{P}<0.01$ stands for extremely significant difference, the details of analysis result is as follow.

\subsection{The difference analysis on rural teachers' living needs}

\subsubsection{Gender issues/difference toward living needs}

In terms of living needs, both male and female teachers report a $P$ value of 0.000 , less than 0.001 , this indicates significant difference between male and female. For comparison of average, male teachers' average score is 20.92, obviously less than their female partners' 24.16 , which means female teachers have a higher degree of satisfaction than their counterparts in this dimensionality, and this difference can be explained by sexual difference in social division of labor. Male are generally regarded as the main bearer of social occupations, they tend to undertake more roles and tasks compared with their female partners, therefore, males tend to hold higher expectations for social benefits and rewards and hope to guarantee the living needs of their very families.

\subsubsection{Living needs difference in teachers with or without a official budget}

Teachers with or without a official budget post report a $\mathrm{P}$ value of 0.004 in terms of living needs, less than the average point 0.005 , again illustrates a difference among teachers with or without an official budget post, more specifically, substitute teachers' average value lower than that of state-run teachers. According to the interview, most of the substitute teachers report a monthly income of 600-800 RMB, while state-run teachers get 1500-2500 monthly, almost 3 times more, it's quiet clear that this remarkable income gap lead to the lower level of satisfaction in terms of living needs, as a result, this may directly cause supply teachers' occupation slack, even impact their quality of teaching. 


\subsubsection{Living needs difference in teacher's educational background}

In dimensionality of living needs, teacher with various educational background report a $P$ value of 0.001 , far more less than the 0.005 , showcase the great living needs diversity in terms of educational background. The average score of teacher with three particular backgrounds are: secondary normal school or elow-23.94; college degree-24.14 and for those hold a bachelor degree, it's 20.99. Teacher who hold a higher degree tend to be less content in aspect of living needs, and vice versa.

\subsubsection{Analysis and comparison between economic income and workload, leisure life and family care.}

Economic income, workload, leisure time are key factors that determine the teacher quality of work life, only when those determining factors reached a balance can them benefit teachers' wellbeing and continued development. Teachers' sustainable development is not only referring to physical fitness and mental health, but also to the sustainable development of career and their role in boosting family development as a core member.

\subsubsection{Survey on teachers' economic income}

In question 9, only 12.1 percent of candidates think their current income is enough for living, while those think their wages are insufficient account for 33.2 percent; in question 16, only 40 percent of teachers report a well-pleasing income; and in question 33, 33.6 percent of them believe school have provide health welfare to them; for question 34, those who think their wages have upturn their living standards only make up 36.4\%. Most of the teachers get 1500-2500 RMB per month and include various kind of premium, say 600 Yuan, nearly no other welfare except for wages, and only get additional 30 Yuan for holidays and festivals, to boost household cost, some teachers have to working odd jobs during summer and winter vocation. All those statistic data and interviews mirrored the unavoidable fact that rural teachers' economic income welfare are less than satisfactory, some teachers even complain about this poor situation. Usually speaking, material is basic necessary in maintain people's daily life, how can we talk about 'quality' if there is no sufficient basic wages for rural teachers, the discontent treatment for teachers illustrate the embarrassing quality of work life.

\subsubsection{Survey on teacher's workload}

Three items in the questionnaire, namely 6(I can handle everything, both in work and in life, easily), 12(my work does not interfere with my leisure life) and 31(I can deal with things at work effectively) are concerned about teacher's workload. A descriptive statistic of workload can be seeing as the follow (table3):

Table 3: descriptive statistics

\begin{tabular}{|c|c|c|c|c|c|}
\hline & $\mathrm{N}$ & minimum value & maximum value & mean value & Standard deviation \\
\hline question 6 & 238 & 1 & 5 & 3.05 & .937 \\
\hline question 12 & 239 & 1 & 5 & 2.24 & 1.121 \\
\hline question 31 & 239 & 1 & 5 & 3.01 & .855 \\
\hline
\end{tabular}

Can be see clearly from table 3 that all the items related to workload score comparatively low, especially in "my work does not interfere with my leisure life", which report a average point of 2.24 , and this manifested a much heavy workload on rural teachers, it may be hard for them to achieve a balance between work and life. Usually, teachers' work could influence their family lives and leisure activities in some extend, what worth mention is that, during our interview, many teachers said they have 4 to 5 classes per day and have to cope with trifles in and out of classroom. As more as 25 percent teachers work 10 hours a day in school, barely have time to take a rest, not mention to tutor their own child's homework. For some primary school, even "Self-contained classes" existed for the shortage of teachers, which means one teacher in charge of all the subjects of one class. All this vividly illustrate the relatively heavy workload on rural teachers, the work conditions for rural teachers are clearly not ideal.

Heavy workload and long work hours leave them no time to take care of their families and take a rest. In stark contrast, the wage and treatment for rural teachers are barely satisfactory. To improve living conditions, they start to seek extra income sources and it's not uncommon to see teachers "half teaching and half farming" or do odd jobs during vacations. This kind of "part-timing" would affect both quality of school education and quality of teachers' own work life. 
To sum up, the imbalance of workload and payment, leisure life and family care impact teachers' quality of work life, thus go against with teachers' sustainable development, and the healthy development of education.

\section{4 difference analysis of esteem needs}

\subsubsection{Esteem needs difference in terms of gender}

The gender $P$ value is 0.003 in terms of esteem needs, less than 0.005 , which tells the difference of esteem when it comes to gender. Apparently, females' average values of esteem needs are higher than that of their counterparts. This difference may also connected with the social roles men hold, as males are generally regarded as primary enabler with high expectations, therefore, more esteem needs are needed compared with female teachers.

\subsubsection{Esteem needs difference in terms of various educational backgrounds}

The finding by analysis shows that teacher with various educational backgrounds differed in esteem needs, teachers' mean value in this dimensionality increased correspondently as they furthered their educational level, this may mean that the better educational background teacher hold, the more esteem needs are required in a certain extent. For this reason, it makes sense to improve rural teachers' education level as it connected tightly with their esteem needs.

\subsubsection{Esteem needs varied with teacher's position difference}

It can be seen from the result of comparison of average that teachers who in a higher position reported a relatively high needs in esteem and vice versa. Obviously, teachers' degrees of satisfaction in esteem needs are impacted by their titles.

\subsubsection{Esteem needs changed within different teaching stages}

By using LSD multiple comparison, striking difference are found among teachers in different teaching stages, where primary school teachers score the highest, while middle school teachers have lowest points, this can be attributed to primary students' sense of owe toward teachers, thus they tend to show more respect to teachers around them. When it comes to senior middle school stage, a sense of rebellion is growing and they want to behave more personally, and in this way, less esteem and respect are given to teachers accordingly.

\subsubsection{Survey on rural teachers' democratic participation and administration}

\subsubsection{School leaders' adoption of teachers' advices}

In the questionnaire, questions related to this subject are item 14(school has a countermeasure to adopt teacher' advices) and 23(school leaders often listen and adopt my advices). According to the data analysis, only 26 percent of teachers' advices are listened and adopted, as much as 76 percent teachers hold that leaders "object to adopt" or they are "unsure" about it. Most of the teachers are still in an auxiliary status, their opinions and suggestions are hardly heard, not to mention adopt, headmasters are still the ruler in school management and policymaking.

\subsubsection{Survey on schools' democratic management}

Question 15(teachers' outstanding performance will be recognized by leaders) and 25(school reward teachers according to their performance) are related with democratic management separately. By analyzing the collected data, only $34.7 \%$ of the schools are rewarding teachers according to their performance. A headmaster tell us in the interview that they usually divide the merit pay, thus factors like seniority and teaching results are ignored in teachers' evaluation, hence this kind of approach damp down their enthusiasm of work and impact the quality of education. 


\subsection{The difference analysis on rural teachers' social needs}

\subsubsection{Analysis on teachers with different general information}

Interestingly, the difference existed only in school type, no particular difference in other aspects such as gender and family income etc; however, it's not surprising that primary school teachers score highest as no pressure of senior high school entrance examination and college entrance examination(both exams are important for Chinese students) on them, thus no fierce competition among teachers, which in turn helps to create a simple relationship among teachers or between teachers and leaders, all that contribute to the higher degree of satisfaction among primary teachers.

\subsubsection{Survey on rural teachers' interpersonal relationships}

Good interpersonal relationship is both an essential part of good school atmosphere and a determining factor of teachers' quality of work life, in which the relationship between teachers, teachers and administers, teachers and students are included.

\subsubsection{Teacher-teacher relationship}

Question 3 (my colleagues will help me when a hand is needed), question 5 (we get along well with each other) and question 21 (we can be frank with each other) are related with teachers' interpersonal relationship.

Survey on teachers' interpersonal relationships

Descriptive statistics

\begin{tabular}{|c|c|c|c|c|c|}
\hline & $\mathrm{N}$ & Minimum value & Maximum value & Mean value & Standard deviation \\
\hline question 3 & 239 & 1 & 5 & 4.37 & .756 \\
\hline question 5 & 239 & 2 & 5 & 4.67 & .507 \\
\hline question 21 & 239 & 1 & 5 & 4.33 & .748 \\
\hline available N (list state) & 239 & & & & \\
\hline
\end{tabular}

We can get to know from the table that the mean value of all the three questions are above 4.3 , it can be safely concluded that teachers are in harmonious relationship with each other, the intimate relationships are fostered among them through various teaching and recreational activities and there are hardly conflict of interests. Generally speaking, teachers can exchange opinions smoothly and will help each other when facing difficult situations.

\subsubsection{2 for teacher-student relationship}

In question 18: I can get along with students and get their respect. $89.1 \%$ out of all hold that they get along well with students, manifested a mean value of 4.28 , we can conclude that teacher-student relationship is harmonious, teachers' work are accepted and respected by students.

\subsubsection{Teacher-leader relationship}

$75.3 \%$ out of all can conduct their own teaching activities without interference from leaders. And $56.6 \%$ of them reported that they often get leaders' appreciation. In a word, teachers' works are usually praised and recognized by leaders.

In conclusion, interpersonal relationship in primary and middle schools are relatively simple, teacher-teacher, teacher-student and teacher-leader relationships are kept in a proper degree of harmoniousness. The normal development of this relationship provide them with a sort of satisfaction, teachers' QWL in this respect is good.

\subsection{Difference analysis on rural teachers' security needs}

Teacher with various educational backgrounds reported a $P$ value of 0.000 (which is less than 0.001 ) in terms of security needs; this indicated that difference existed among teachers with different education backgrounds. The average scores are: 26.00 for secondary normal school degree graduates, 26.58 for college graduates and 27.51 for teachers with bachelor degrees separately. Usually, teachers with better educational background may show more stability in work -at 
least to a certain degree, and may report a higher degree of satisfaction in security needs.

\subsubsection{State-run teachers' work is relatively stable, while that of supply teachers are not}

\subsubsection{Few rights and interests are guaranteed for supply teachers}

With a relatively high proportion of totally 87.44 percent, plus they tend to have teachers' authorizations and usually would not be fired, in this aspect; the statistic analysis can generally reflect the stability in their work. However, for the supply teachers who do not have formal authorizations, some rights and interests can not be guaranteed. Some supply teachers said in the interview that they get about 600-800RMB per month with no additional welfare, they may also get fired someday, thus it is not surprise to see they have a lower degree in both living needs and security needs. Recently, in order to stimulate teachers' enthusiasms and improve teaching quality, some schools figured out many ways to push teachers forward, for example, send poorly performanced teachers to worse schools, adding more pressures on teachers and affecting their QWL.

\subsubsection{Work environment are relatively safe, while physical environment are poor}

For question 10(I think my work environment is safe, no occupation injuries will happen), 193 teachers agreed to some degree, accounting for 80.8 percent. While they get a safe working environment, the physical conditions around them are quiet poor. Generally speaking, physical conditions include working environment and working conditions, after the Wenchuan earthquake, many school tried all possible means to raise funds, as a result, some dangerous buildings are reconstructed and working environment safety are improved, yet no substantial improvement in terms of working conditions: schools are still facing shortage of labs, teaching attachments etc. According to the survey, only those town middle schools and central primary schools have their own libraries, almost all schools have no labs, not to mention multimedia classrooms.

\subsection{Difference analysis on teachers' self-actualization needs}

\subsubsection{Gender difference in self-actualization needs}

The gender $P$ value in this dimensionality is 0.004 , less than 0.005 , means a difference existed between males and females. Female teachers' mean value are higher than that of male teachers, this difference may have connections with traditional culture of China, as the main bread earner of a family, more expectation are added to man roles, thus for male teachers there are more expectations for them, while their counterparts are better off in this aspect, it is not surprise that they have a comparatively high degree if satisfaction in self-actualization needs.

\subsubsection{Self-actualization needs difference in school type (nature of school)}

The data indicated obviously that the nature of school can impacts teachers' self-actualization needs significantly. In this dimensionality, the mean value of key school teachers is higher than that in general schools, and teacher wok in weak schools reported the lowest points. Teacher works in key schools tend to achieve their self-realization more easily and hold a higher degree of satisfaction, while teachers from weak schools reported a low level of self-actualization.

\subsubsection{Teaching stages difference in teachers' self-actualization needs}

It can be conclude from the survey that teachers work in middle school have the lowest points in terms of selfactualization, that is because when compared with naïve pupils and high-pressured high school students, middle school students are reaching their treason of psychological development, and their self-awareness is very immature, teachers tend to feel frustrated and tired in dealing with them, and there are merely pleasure and sense of achievement. 


\subsubsection{Issues about esteem and self-actualization in rural teachers' occupational development}

Table 5: Descriptive statistics of teachers' sense of achievement: Descriptive statistics

\begin{tabular}{|l|c|c|c|c|c|}
\hline & N & minimum value & Maximum value & Mean value & Statistic deviation \\
\hline $\begin{array}{l}\text { Question 1( there are enough professional } \\
\text { autonomy in my work) }\end{array}$ & 239 & 1 & 5 & 3.87 & 1.110 \\
\hline Question 8( there are creativeness in my work) & 239 & 1 & 5 & 3.58 & 1.101 \\
\hline Question 4( working can promote my performance ) & 239 & 1 & 5 & 4.34 & 0.839 \\
\hline valid N ( list status) & 239 & & & & \\
\hline
\end{tabular}

Question 1 is "I can decide my own work manners and content", question 8 is about "my work is full of creativity" and question 4 is titled "I can learn new skills from other in my work". All items related to sense of achievement scored above 3.5 , giving a rather high degree of satisfaction in this dimensionality. However, there are still many problems existed under the exam-oriented education background. Facing arduous teaching tasks, and with most of the times spent on teaching, no much spare time in preparing courses and correcting homework, not to mention deal with students' affairs. For schools, the most important indicator of teacher' performance examination is enrollment rates and student's test result, both the very subject teachers and class teacher will be blamed for students' poor test result, even in danger of deducting salary. This kind of performance review is not only unfair for them, but also weakened their creativity and autonomy in regular teaching activities.

Table 6 : Statistics on teachers 'career development : Statistic magnitude

\begin{tabular}{|c|c|c|c|c|c|}
\hline & $\mathrm{N}$ & minimum value & maximum value & Mean value & standard deviation \\
\hline Question 19 & 239 & 1 & 5 & 2.72 & 1.080 \\
\hline Question 24 & 239 & 1 & 5 & 2.18 & 1.275 \\
\hline
\end{tabular}

Question 19, 24 are "school can help me to realize my potentiality, which makes me do better job in my professional field", "school offers many opportunities for me to take further education" separately. It's not hard to find that the satisfaction degree in aspects like chance to fulfill potentiality and further study are comparatively low, especially in terms of further education. Through the analysis of data, it was found that 57.8 out of 100 teachers never attended a training course, and some teachers even revealed in the interview that: for most of the time, teachers attend training programs are actually travel around, what's more, those who participating in further study programs are usually either leaders or backbone teachers. As to the training content, nothing is particular new and all about commonplaces; it's hard to keep peace with the current development of education.

\section{Summary}

By analyzing all those data, it's easy to know that in the five dimensionalities of rural teachers' QWL, rural teachers in Shanxi Provence have relatively high satisfaction level when it comes to social needs and security needs; they tend to have harmonious interpersonal relationships and fell sound and safe in their work conditions, but most of them are dissatisfied with their physical environment; however, the overall satisfaction level towards living needs, esteem needs and self-actualization needs is low. There is a popular belief that they are not paid enough and their social status and occupation reputation are unsatisfactory, or their democratic participation and management in school affairs are limited, or there are merely further study chances, overall, the rural teachers' QWL in Shanxi Provence belonging to the lower middle level.

Lower quality of work life will definitely bring harms like: (a) teachers' discontented with work and life may lead occupation slack and make them unwilling to work hard; (b) Bring about instability of teaching stuff in compulsory education stage, for some excellent teachers reject to work in primary and middle schools, even less willing to work in rural areas; and (c) low quality of work and life will also lead to unhealthiness both mentally and physically, which is often the trigger of extreme events, bringing harm to students, colleagues, even hamper the sustainable development of education(Mao Zuoxiang,2008). 


\section{Coping Strategies for Improving Rural Teachers' QWL}

\subsection{Establish a reasonable salary system to improve their remuneration dynamically}

The item 25 of Teacher's Law expressly stipulated that "teacher's average wage level should not lower than or above that of national public servant", yet teacher's salary is obviously less than public servant's due to various reasons. The research of Wang Lan (2009) noticed that in some places, it is not uncommon to see teachers' salaries are unpaid for months that are unfair for them. As it mentioned before, the average payment of teachers' wages are 1500-2500 RMB per month, and urban teachers' favorable medical insurance and housing funds cannot enjoyed by rural teachers, it's hard for them to deal with children's schooling and house construction.

Concerning this issue, local governments should set aside special funds and make sure that a fixed sum is for a fixed purpose only, also, the issue of remuneration and related awards must take fairness into consideration. In order to make teachers' remuneration are match with their very contribution, schools of different places should formulate their own performance assessment systems in line with their practical situations, in this case can they reach a destination of "more pay for more work and less pay for less work". Secondly, government should work on how to improve their payment dynamically, to make sure that their income increases are keep peace with GDP increase, thus truly achieve the goal of "teachers' payment are the same with public servant's" (Jin Cuican, et al, 2011).Lastly, some fund compensations should allocated to teachers from the wide social resources, for example, using the wide social donation and establish special funds for rural teachers' allowance.

\subsection{Improve the physical conditions and optimize the working environments}

Firstly, some schools' curriculums arrangement is highly centralized as in shortage of teaching stuff, they complain that they have courses all day long occasionally, this severely jeopardized their health. In consideration of this serious situation, schools should take teachers' actual workload into account and plan their course scheduling reasonably. In the second place, schools should offer teachers a comfortable working place, ample and bright classroom and office, fresh environment by redesigning and reconstructing the overall school environment. Last but not the least; improve the physical environment for them, such as setting up laboratory, perfecting the teaching materials, buying new teaching instrument and promoting educational informationlization.

\subsection{Set up a teacher-centered democratic management system}

(a) School leaders and educational administrators should lay emphasis on humanity management which is teacheroriented. Respect teacher' principle status and independent personality; (b) encourage teacher's participation in school affairs and create a management environment where teachers are welcomed; (c) open school affairs to public, school should publicize all the important decision-makings and those policies related to teacher's vital interests, in order to make it more transparency; (d) encourage the free airing of views, embrace the reasonable advices proposed by teachers.

\subsection{Set up a scientific and reasonable teacher evaluation mechanism}

The evaluation for teacher' teaching achievement should be comprehensive and objective, and guarantee the fairness during the evaluation. In addition, for the education sectors, a scientific approach to evaluate teacher's achievement should be implemented in order to change the current popular marks-oriented assessment mechanism, for example, student's evaluation on teacher, mutual evaluation among teachers, developmental evaluation mechanism etc.

\subsection{Pay attention to teacher's progress and intensify teacher's training}

The phenomenon that "give more emphasis on pre-service cultivation while less on induction training and post-profession training, and lay too much emphasis on education background training will definitely impose restricts on the development of education in rural areas " (Wang Lan,2009). Firstly speaking, teacher's colleges should not only import talents to rural schools by training teachers for special posts, but also offer some courses according to the very rural education conditions. Next, lay more emphasis on both induction tutoring and after profession training, guarantee teacher's professional sustainable development. The training content should cover subjects such as teaching ability, teaching 
ideas, psychical training and so on, special attention should paid on preeminent the cultivation of teachers and backbone teachers as their leading role in teaching and working. Finally, teacher training is the act of government and should be mainly state-funded, it is necessary to increase training fee and establish a relative supervision and responsibility mechanism, after a total planning and scientific assessment.

\subsection{Attach importance to teacher's physical and mental health, relief occupational pressure and job burnout}

It is well recognized that teacher's occupational pressure and job burnout are not only jeopardize their physical and mental health, but also affect their working enthusiasm and hinder the acquisition of satisfactory teaching result. To deal with this, teachers should figure out the source of occupational pressure and job burnout and suit the remedy to the very case. For instance, enhance physical excise and alternate work with rest; it's also necessary to communicate more with colleagues, create an atmosphere of mutual-learning and mutual-helping; besides, keep learning new knowledge and ideas, enhance the level of expertise and operational capability.

To sum up, to improve rural teacher' QWL, its necessary to start with things like improving their salary welfare, management model, working environment and conditions, and training etc. it's a well established fact that the competition of talents is competition of education on earth, as the main force of rural education, rural teacher's QWL has a direct influence both on rural areas' ability to maintain and attract talents and on the quality of compulsory education in that broad area. More over, as Shu Xiaoyan (2009) put it: "teacher's QWL is a dynamic indicator, and also an indicator that can be improved through concerted effort". It's really urgent for rural schools to enhance teachers' QWL and realize the common interests of schools and teachers thus keep the healthy and sustainable development of compulsory education in rural areas and cultivate more talents for the country.

\section{References}

Ahmed, N. Quality of Work Life: A Need for Understand[J]. Indian Management, 1981, 20 (11:29 33.

Cai Xiaowu, Liao Chuanjing. 2013 The Research of Correlation between Job Burnout and Quality of Work and Life of College Young Staff. 1(2):54-58

Chen Hua et al. Explore the Relationship between High School Teacher's Work Family Conflict and Quality of Work life. Science of Social Psychology. 2007,93-94(5-6): 157-160

Jia Haiwei, Guo Fenglan. Deliberation and Analysis of the Quality of Work life of Faculties of Universities and Colleges. Journal of Hebei University of Science and Technology. 2005,5(4): 88-92

Jia Haiwei. Indistinct Synthetic Evaluation Model of The Quality of Work life of Teachers of University and Colleges. Journal of South China Agriculture University (Social Science). 2005, 4(3): 88-91

Jin Cuican, Li Jiaxiao, et al. Thoughts on improving the sensation of happiness in rural teachers. Culture and history vision (theory). 2011, (11)75-77

Lei Ticui. How To Increase Teacher's QWL. Petroleum Education. 2000, 103(12): 60-62Sun Yuhua. Study on Rural Area Teacher's Quality of Work Life (QWL) Education Science. 23(3):58-63

Liu Qing, Feng lan. The Analysis on Young College Teaching Stuff's Quality of Work life-based on the Sample Survey of Wuhan City. Journal of Nanjing College for Population Programmed Management. 2007, 23(1): 21-23

Luo Ruguo. 2012 The Review and Reflection of Teachers' Quality of work life. Journal of Northwest Normal University (Social Science) 49(1):107-112

Mao Zuoxiang. Research on Teacher's QWL of YB County- the Management Problems and [11] Improvement Countermeasures for Several surveyed Schools in Western Areas. Shanghai: East China Normal University. 2008

Shu Xiaoyan. Explore and analyze the Quality of Work life of High School Teachers. Journal of Teaching and Management. 2009. 19: 18-20

Sun Yuhua. QWL: Study on Humanity of Teacher's Work and Life. Comparative Education Review. 2008, 219(4): 62-67 Sun Yuhua. Study on Rural Area Teacher's Quality of Work Life (QWL) Education Science. 2007, 23(3):58-63

Wang et al. survey on teacher's QWL in primary and middle schools- the case of Jiangxi Provence. Educational Measurement and Evaluation. 2012,(1): 28-31

Wang Hong, Wang Yang. Primary Analysis on Quality Improvement of Work Life for College Teachers. Researches in Medical Education. 2005, 4(4): 275-277

Wang Nan. The reflect on measures for improving rural teacher's living condition-based on the research in Hei Longjiang Provence. Journal of Shan Xi Vocational and Technical Institute. 2009.15(4): 56-59.

Xu Xiaodong. Evaluation for the researches on QWL. Advances in Psychological Science. 1993, 1(1): 8-13

Yang Huadong, Shi Kan. A cross-cultural research of educational reforms affecting teacher's QWL. Psychological Development and Education. 2001,9 (1):40-46

Yu Jin, An Investigation of Work life Quality in Teaching Stuff of Jilin city. Journal of Changchun University. 2002, 12(2): 70-71

Zhao Shouyin et al. The Process of Developing Questionnaire for Teacher's Quality of Work Life. Psychological Science. 2010, 33(3): 290-294 